\title{
Journal of Human Anatomy
}

\section{Anatomical Reasons and Clinical Significance of Headache: From Basics to the latest}

\section{Singh D* \\ Emeritus Professor of Anatomy, KG's Medical University, Lucknow, India}

*Corresponding author: Dhanraj Singh, Emeritus Profesor of Anatomy, K.G's

Medical University, Lucknow, E-mail: dr.drsingh40@gmail.com

\section{Mini Review \\ Volume 1 Issue 1}

Received Date: February 06, 2017

Published Date: May 02, 2017

\section{Mini Review}

Headache, the commonest neurological disorder, is one of the humanity's most common medical complaints; most people experience them at some point in their life. According to the World Health Organization (WHO) reports almost half of all adults worldwide will experience a headache in any given year. Among first 20 causes of disabilities migraine WHO declared headache as the most disabling medical condition experienced worldwide. The headache can affect anyone regardless of age, race, and gender. In the ancient time Charak (Circa 100 BC) described five types of 'shirashool'; Sushurut reported eleven types of 'anyatovat' including migraine and trigeminal neuralgia.

The headache is caused by more than 300 causes [1]. Most patients with headache requiring medical attention need CT/ MRI only a small proportion of headache pts need investigation [2]. Committee of International Headache Society 1988 (revised in 2004) [3], 14 main types of headaches are classified into [4-10]:

\section{The Primary Headaches}

1. Migraine

2. Tension - type $\mathrm{H}$

3. Cluster $\mathrm{H} \&$ other trigeminal autonomic cephalalgias (TAC)

4. Other primary headache disorders

\section{Secondary Headaches}

5. Attributed to head and / or neck trauma

6. Attributed to cranial and / or cervical vascular disorder

7. Attributed to non - vascular, non - infections intracranial disorder

8. Headache attributed to a substance or its withdrawal

9. Headache attributed to infection.

10. Attributed to disturbance of homeostasis.

11. Attributed to disorders of cranium, neck, eyes, ears, nose, sinuses, teeth, mouth, other facial or cranial structures.

12. Attributed to psychiatric disorder.

13. Cranial neuralgia.

14. Other headaches, cranial neuralgia, central or primary facial pain.

\section{Pain sensitive Intracranial Structures}

1. Portions of dura mater near blood vessels

2. Dural arteries, large veins and venous sinuses

3. Arteries of circle of Willis (base of brain), first few $\mathrm{cm}$. Medium-sized branches

4. Pial vessels

5. Cranial nerves II, III, VI, V, IX, X and Cervical 1-3 spinal nerves 


\section{Extracranial Structures}

6. Scalp and neck muscles

7. Skin, cutaneous nerves mucosa of nose, air sinuses, teeth (pulp) external carotid a \& branches

\section{Pathogenesis of Headache}

- Irritation of meningeal lining

\section{Journal of Human Anatomy}

b) Blood in subarachnoid hemorrhage

- Displacement, distention distortion or traction of blood vessels, large veins, sinuses

- Irritation, stretching, compression, distortion of sensory nerves, most often V, IX, X, C1-3, tumours, aneurysms

- Muscle contraction or spasm

- Raised or lowered intracranial pressure

a) Inflammation

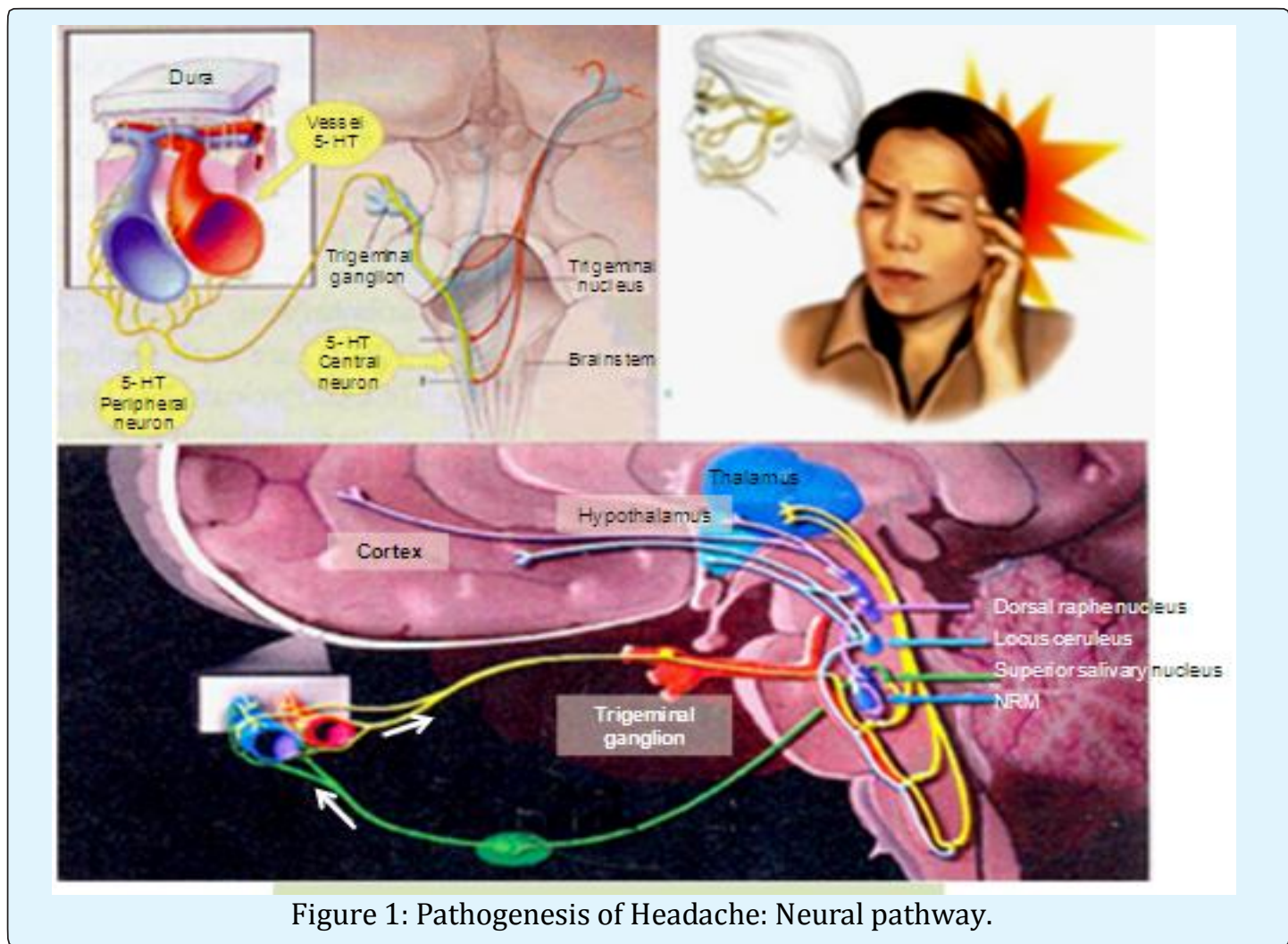

\section{Ice cream Headache}

- Cold stimulus headache

- Extremely cold substance contacts roof of mouth and upper incisors (Boes etal. 2004)

- Most often midfrontal pain, peaks in 20-60 s.

- Complaint most often in migraineurs than gen. population (may feel on same side as migraine)

- Pathogenesis unclear. Reflex vasoconstriction?

- $\downarrow$ Skin temp. forehead by $1^{\circ} \mathrm{C}$

\section{Headache in Women}

- Change in oestrogen: headache with menarche, menstruation, pregnancy and menupause

- $14 \%$ have migraine only during menstruation or in premenstrual syndrome
- Headache as complication of pregnancy

- SAH

- Pseudotumor cerebri

- Migraine may be ameliorated by pregnancy but tension type headache is not affected

\section{Useful Practical Points}

- Migraine is the most common form of headache

- The initial attack may suggest more serious causes, particularly if associated with focal symptoms and signs

- Beware of diagnosing migraine beginning after the age of 50

- Consistently lateralised hemicrania with persisting symptoms, signs or a skull bruit require further investigation 


\section{Journal of Human Anatomy}

- Migrainous neuralgia affects middle-aged men with attacks of severe periorbital pain often awakening the patient

- Treatment of migraine relies on rest, reassurance, metoclopramide (or other antiemetics and simple analgesics

- $\quad$ Ergot derivatives may help about one half of migraineurs. Beware of ergot habituation with the development of withdrawal headache

- Frequent migraine attacks require preventive treatment with regular medication, e.g. pizotifen, pro-pranolol, methysergide, Amitriptyline.

- Cough headache may occur with raised ICP, posterior fossa lesions and as a benign entity

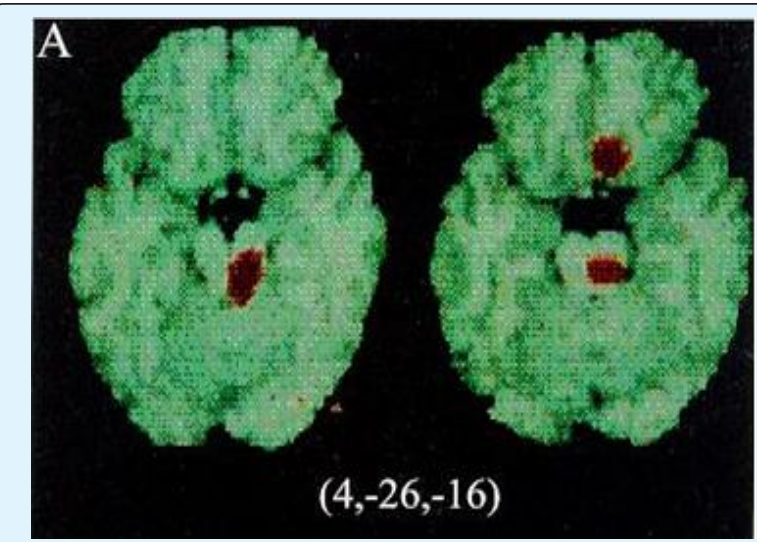

Figure 2: Posterior fossa lesions.

\section{Migraine in Children}

- $\quad$ Common- 7 yr (3\%), 14 yr (11\%)

- Shorter duration

- Bilateral or unilateral

- Phonophobia or photophobia

- Syndromes of childhood migraine

- Vertigo

- $\quad$ alternating hemiplegia

- $\quad$ Nausea vomiting (every 30- 40 days)

\section{Central Modulation of Headache}

- Rostral brainstem is crucial

- Discrete lesions of brainstem and locus ceruleus

- $\quad$ CBF through $\alpha 2$ adrenoreceptor in occipital region by $25 \%$

- Corresponding extracerebral vasodilatation, $5 \mathrm{HT}$ containing neurons in brainstem dorsal raphe nucleus.

\section{Headaches Unclassified}

Certain distinctive forms of headache defy classification under the above scheme for it is unclear whether they involve: a peripheral, nociceptive cause or a neurogenic cause.

Cluster headache is characterized by episodes of severe orbital pain lasting 15 minutes to three hours [11-15], occurring one or more times a day in bouts lasting weeks or months, followed by pain-free intervals. Distinctive associated features are ipsilateral lacrimation, conjunctival injection and nasal obstruction [16-19]. The mechanism of cluster headache is unknown but may involve central dysmodulation of pain, triggered from the hypothalamus. In contrast, the mechanism may involve oedema of the cavernous portion of the internal carotid artery [20-24]. Resembling cluster headache is paroxysmal hemicrania which is characterized by attacks of sustained hemicranial pain lasting 15 minutes each, recurring six to 30 times a day for periods of three to six weeks.

Like cluster headache, paroxysmal hemicrania is associated with parasympathetic features on the ipsilateral side. Its cause is unknown but may involve a source in the cervical spine. Diagnostic is the response of this form of headache to. Indomethacin

\section{Diagnostic Considerations}

When headache is episodic and recurrent and follows a well-established pattern, the patient likely has a primary headache disorder (i.e, headaches with no organic or structural etiology). Differentiating migraine from other primary headaches (e.g, muscle contraction tension headache, cluster headache) is important, as optimal treatment may differ.

Migraine may also may simulate or be simulated by secondary headache disorders or coexist with a secondary headache disorder [25-29]. Any of the following features suggest a secondary headache disorder and warrant further investigation:

- The first or worst headache of the patient's life, especially if rapid in onset

- A change in frequency, severity, or clinical features of the attack

- New progressive headache that persists for days

- Precipitation of headache with Valsalva maneuvers (i.e, coughing, sneezing, bearing down) 


\section{Journal of Human Anatomy}

- The presence of associated neurologic signs or symptoms (e.g, diplopia, loss of sensation, weakness, ataxia)

- Onset of headaches after the age of 55 years

- Headache developing after head injury or major trauma

- $\quad$ Persistent, 1-sided throbbing headaches

- Headache accompanied by stiff neck or fever

- Atypical history or unusual character that does not fulfill the criteria for migraine

- Inadequate response to optimal therapy

\section{Crash Migraine}

Severe headache of sudden onset is a concern despite its occurrence in primary headache disorders. Migraine headaches may have an abrupt onset; these are termed "crash" migraine headaches and are similar to a "thunderclap" headache [30-33]. Cluster headache also may be sudden and excruciating, but it lasts only 15-180 minutes and is recognized easily if the patient has had previous attacks.

\section{Exertional Headache}

Exertional headaches are precipitated by strenuous activity (eg, running, coughing, sneezing, Valsalva maneuver) and build in intensity over minutes. They are particularly common in patients who have an inherited susceptibility to migraine. Coital headache is a type of exertional headache that can develop at the height of orgasm or it may build up through intercourse.

\section{Intracranial aneurysm}

Despite the possibility of a benign cause, a ruptured intracranial aneurysm is the primary consideration if the headache is severe and of sudden onset and reaches maximum intensity in minutes. The classic presentation of an aneurysmal subarachnoid hemorrhage (SAH) is as follows:

- Severe headache with sudden, explosive onset

- Stiff neck

- Photophobia

- Nausea and vomiting

- Possibly, alteration of consciousness

\section{References}

1. Bin D (1978) Headaches and head pains associated with diseases of the ear, nose and throat, Med Clin N Am 62(3): 523-531.
2. Bland JH, Davis PH, London MG et al. (1963) Rheumatoid arthritis of the cervical spine. Arch Ini Med 112: 892-S

3. Bogduk N (1930) The anatomy of occipital neuralgia. Clin Exp Neurol 17: 167-84

4. Bogduk N (1982) The clinical anatomy of the cervical dorsal rami. Spine 7(4): 319-330.

5. Bogdck N (1993) Pain of cranial nerve and cervical nerve origin other than primary neuralgias. In: Olesen J, Tfelt-Hansen P. Welch KMA, eds. The Headaches. New York: Raven Press. Pp: 765-772S.

6. Bogduk N (1995) Anatomy and Pathology. In: Olesen J, TfeltHansen P, Welch KMA. (Eds.) The Headaches. New York: Raven Press 49: 435-445.

7. Bogduk N, Lambert G, Duckworth JW (1931) The anatomy and physiology of the vertebra] nerve in relation to cervical migraine. Cephalalgia 1:1-14.

8. Bogduk N, Marsland A (1956) On the concept of third occipital headache. J Neural Neurosurg Psychiat 49(7): 775-780.

9. Bogduk N, Simons DG (1993) Neck pain: joint pain or trigger points? In: Vaeroy $\mathrm{H}$, Merskey $\mathrm{H}$, (Eds.) Progress in Fibromvalgia and Myofascial Pain. Amsterdam: Elsevier pp: 267-273.

10. Cyriax J (1938) Rheumatic headache. Br Med J 2(4069): 1367-1368.

11. Dvorak J, Panjabi MM (1987) Functional anatomy of the alar ligaments. Spine 12(2): 183-189.

12. Dvorak J, Hayek J, Zehnder R (1957) CT-functional diagnostics of the rotatory instability of the upper cervical spine. Part 2: an evaluation on healthy adults and patients with suspected instability. Spine 12(8): 726-731.

13. Fisher CM (1982) The headache and pain of spontaneous carotid dissection. Headache 22(2): 6065.

14. Headache Classification Committee of the International Headache Society. Classification and Diagnostic Criteria for Headache Disorders. Cranial Neuralgias and Facial Pain. Cephalalgia 1988: S(suppl 7)

15. Jensen R, Rasmussen BK, Pedersen B, Lous I, Olesen J (1992) Cephalic muscle tenderness and pressure pain 
threshold in a general population. Pain 48(2): $197-$ 203.

16. Kerr FW (1961) Structural relation of the trigeminal spinal tract to upper cervical roots and the solitary nucleus in the cat. Exp Neurol 4: 134-148.

17. Kimmel DL (1959) The cervical sympathetic rami and the vertebral plexus in the human foetus. J Comp Neurol 112(1): 141-161.

18. Kimmel DL (1960) Innervation of the spinal dura mater and dura mater of the posterior cranial fossa. Neurology 10: 800-809.

19. Lance JW (1993) Mechanism and Management of Headache. 5lh ed. Oxford: Butterworth Heinemann.

20. Langemark M, Olesen J (1987) Pericranial tenderness in tension headache. Cephalalgia 7(4): 249-255.

21. Lord SM, Barnsley L, Wallis BJ, Bogduk N (1994) Third occipital headache: a prevalence study. J Neurol Neurosurg Psychiatry 57(10): 1187-1190.

22. Lous I, Olesen J (1982) Evaluation of pericranial tenderness and oral function in patients with common migraine, muscle contraction headache and combination headache. Pain 12(4): 385-393.

23. McCormick CC (1957) Arthrography of the atlantoaxlal (C1-C2) joints: technique and results. J Intervent Radiol 2: 9-13.

24. Olesen J, Tfelt-Hansen P, Welch KMA (1993) The Headaches. New York: Raven Press.

25. Oleson J (1978) Some clinical features of the acute migraine attack. An analysis of 750 patients. Headache 18(5): 268-271.

\section{Journal of Human Anatomy}

26. Ouaknine G, Nathan H (1973) Anastomotic connections between the eleventh nerve and the posterior root of the first cervical nerve in humans. J Neurosurg 38(2): 189-197.

27. Penfield W, McNaughton F (1940) Dural headache and innervation of the dura mater. Arch Neurol Psychiat 44(1): 43-75.

28. Robinson HS (1966) Rheumatoid arthritis: atlantoaxial subluxation and its clinical presentation. Can Med Ass J 94(10): 470-477.

29. Sharp J, Purser DW (1961) Spontaneous atlanto-axial dislocation in ankylosing spondylitis and rheumatoid arthritis. Ann Rheum Dis 20(1): 47-77.

30. Stevens JS, Cartlidge NEF, Saunders M., Appleby A, Hall M, Shaw DA (1971) Atlanto-axial subluxation and cervical myelopathy in rheumatoid arthritis. Quart J Med 40 (3): 391-408.

31. Torvik A (1956) Afferent connections to the sensory trigeminal nuclei, the nucleus of the solitary tract and adjacent structures. J Comp Neurol 106(1): 51-141.

32. Travell JG, Simons DG (1983) Myofascial Pain and Dysfunction. The Trigger Point Manual. Baltimore: Williams \& Wilkins.

33. Vital JM, Grenier F, Dautheribes M, Baspeyre H, Lavignolle B, et al. (1989) An anatomic and dynamic study of the greater occipital nerve ( $\mathrm{n}$ of Arnold). Surg Radiol Anat 11(3): 205-210. 